\title{
Patterns of smoking in Russia
}

Martin McKee, Martin Bobak, Richard Rose, Vladimir Shkolnikov, Laurent Chenet, David Leon

\begin{abstract}
Background-Tobacco is a leading cause of avoidable death in Russia but there is, as yet, relatively little information in the public domain on who is smoking and how this is changing. This information is important for those seeking to develop effective policies to tackle this issue.

Objective-To determine the prevalence of smoking in Russia and its association with sociodemographic factors.

Design-Cross-sectional survey on patterns of tobacco consumption.

Setting-Data were collected using the New Russia Barometer, a multi-stage stratified-sample survey of the population of the Russian Federation undertaken in the summer of 1996.
\end{abstract}

Participants-Data were available on 1587 individuals (response rate $65.7 \%$ ). Respondents differed little from the overall Russian population in terms of age, sex, education, and voting intention.

Main outcome measures-Prevalence of current and past smoking.

Results-Smoking is common among males of all ages and in all areas. Of those aged 18-24 years, $65 \%$ smoke, rising to $73 \%$ in those aged $25-34$ and then falling steadily to reach $41 \%$ in those aged 65 and older. Among women, smoking is much more common among the young $(27 \%$ in those aged 18-34) than among the middleaged and elderly $(5 \%$ in those aged 55 and older), and more common among those living in urban areas than in rural areas. Smoking is also more common among men and women suffering material deprivation but there is no independent association with education. Among men, but not women, church attendance is inversely associated with smoking. In both sexes, but especially women, heavy drinking and smoking are associated.

Conclusions-Tobacco poses a major threat to the health of future generations in Russia, especially among women. A robust policy response is required.

(Tobacco Control 1998;7:22-26)

Keywords: prevalence, Russia, smoking

\section{Introduction}

Tobacco consumption in Russia faces further upward pressure as transnational tobacco companies take advantage of the opportunities arising from the opening of markets. ${ }^{1}$ This is in a country in which rates of smoking-related death are already high and have been climbing. Using a method based on estimates of the fraction of particular causes of death attributable to smoking, Peto et $\mathrm{al}^{2}$ estimated that smoking accounted for $30 \%$ of all male deaths ( $42 \%$ in the age group 35-69 years) but only $4 \%$ of female deaths ( $6 \%$ in the age group 35-69) in the Russian Federation in 1990. This equates to an average of 17 years of life lost per death from smoking. Expressed in another way, they estimate that more than one in five Russian men aged 35 will die from disease attributable to smoking before reaching age 69, based on 1990 death rates. These figures indicate the importance of tobacco as a cause of premature death in Russia and the need for an effective policy response. The present survey seeks to determine the prevalence of smoking in an nationally representative sample of the Russian population and to obtain information on sociodemographic factors associated with smoking. This information, which has previously been unavailable, will be necessary for the development of such a response.

\section{Methods}

The New Russia Barometer (round 6) was undertaken by the Russian Centre for Public Opinion Research (VCIOM) between 25 July and 2 August 1996. The methods have been described in detail elsewhere ${ }^{3}$ but, in brief, it was a multistage, stratified sample of the population of the Russian Federation in which the Federation was first divided into 22 regions, then into urban and rural areas, and then, for urban areas, by population to give regional centres and other towns. Within that framework, towns were randomly selected with a probability equal to their share of the total population. A total of 69 urban and rural settlements were selected. A total of 161 trained interviewers were used. Unit

Table 1 Characteristics of sample compared with Goskomstat population estimates for 1993

\begin{tabular}{lcc}
\hline Variable & $\begin{array}{c}\text { Actual } \\
(\%)\end{array}$ & $\begin{array}{l}\text { Expected \% (based on } \\
\text { Goskomstat estimates) }\end{array}$ \\
\hline Male & 45.7 & 45.5 \\
Age (years) & & \\
$18-19$ & 3.6 & 4.7 \\
$20-29$ & 17.7 & 18.3 \\
$30-39$ & 17.6 & 22.2 \\
$40-49$ & 21.4 & 17.6 \\
$50-59$ & 18.1 & 15.1 \\
$60-69$ & 14.7 & 15.3 \\
$\geqslant 70$ & 6.9 & 6.8 \\
Education & & \\
$\quad$ Higher & 15.7 & 14.5 \\
Technical & 21.6 & 21.5 \\
Secondary & 14.4 & 15.8 \\
Vocational & 10.4 & 10.5 \\
$\quad$ Incomplete secondary & & \\
$\quad$ and less & 37.9 & 37.7 \\
\hline
\end{tabular}

Keppel Stral Medicine,

WC1E 7HT, UK

m.mckee@1shtm.ac.uk 
Table 2 Smoking status of Russians (\%)

\begin{tabular}{|c|c|c|c|c|c|c|c|c|}
\hline \multirow[b]{2}{*}{$\begin{array}{l}\text { Age group } \\
\text { (years) }\end{array}$} & \multicolumn{4}{|l|}{ Male } & \multicolumn{4}{|l|}{ Female } \\
\hline & $\begin{array}{l}\text { Current } \\
\text { smoker }\end{array}$ & Ex-smoker & $\begin{array}{l}\text { Never } \\
\text { smoked }\end{array}$ & $n$ & $\begin{array}{l}\text { Current } \\
\text { smoker }\end{array}$ & Ex-smoker & $\begin{array}{l}\text { Never } \\
\text { smoked }\end{array}$ & $n$ \\
\hline $18-24$ & 65 & 13 & 22 & 106 & 27 & 12 & 61 & 99 \\
\hline $25-34$ & 73 & 13 & 14 & 132 & 28 & 13 & 59 & 123 \\
\hline $35-44$ & 71 & 13 & 16 & 166 & 14 & 11 & 74 & 168 \\
\hline $45-54$ & 64 & 22 & 14 & 150 & 12 & 7 & 82 & 165 \\
\hline $55-64$ & 49 & 34 & 17 & 104 & 5 & 7 & 88 & 153 \\
\hline$\geqslant 65$ & 41 & 30 & 29 & 70 & 5 & 7 & 89 & 151 \\
\hline
\end{tabular}

Source: New Russia Barometer VI, 1996.

households were listed in address order and, starting with a random selection, with individuals matching an age by gender by education grid.

The survey was designed primarily to assess sociodemographic, economic, and political factors but also contained some questions on health. The data on which this paper is based are derived from the question: "Do you smoke now? (yes/no)", and if not: "Did you smoke in the past? (yes/no)". From responses to these questions, individuals were categorised as current smokers, ex-smokers, or neversmokers. Questions on alcohol consumption examined frequency of drinking and quantity, expressed as commonly understood measures of vodka, wine, and beer. These were subsequently converted to quantities of pure alcohol.

\section{Results}

Of 3379 households with someone at home, $965(29 \%)$ had no-one who met the requirements of the grid; in $470(20 \%)$ the interview was refused; in $271(11 \%)$ the door was not answered; in $63(3 \%)$ the identified individual was unable to answer; and 11 $(0.4 \%)$ interviews were interrupted. In total, 1599 interviews were completed. For 12 individuals, age was not recorded and these were excluded from the analyses. This gave an overall response rate of $65.7 \%$. The final sample was a close match with data from Goskomstat for the population in 1993 in terms of gender, age, and education divisions (table 1), and questions on voting intentions also corresponded closely with the actual votes cast in the 1996 election.

Among men, smoking is very common in those aged under 50 . It declines relatively steeply among older groups, reflecting largely the relative increase in ex-smokers (table 2). Among women, few over age 50 have ever smoked and even fewer $(6-7 \%)$ are current smokers. The frequency of current smoking decreases considerably with increasing age. If it is assumed that most smokers begin in their teens, the figures for those who have never smoked would be consistent with an interpretation that smoking rates among men may actually be falling in younger age groups but that, among women, they are rising quite rapidly.

When analysed by type of settlement, there is very little difference among men, but among women, current smoking is much more common in Moscow and other cities than in rural areas (table 3).

Analysis by region again shows little variation among men but also shows considerable differences among women, with higher levels in the area around Moscow and in Siberia than in Southern Russia, even after adjusting for urbanisation (results not shown).

Logistic regression was undertaken to explore the association with a variety of possible explanatory variables. The results are shown in table 4 . The definitions of most of the variables are self-evident but material deprivation requires comment. This is a composite variable calculated from responses to questions on whether those in the respondent's family had often (scored as 3), sometimes (2), rarely (1), or never (0) had to go without food, heating, or necessary clothes in the preceding 12 months. In the interests of brevity, the sum of these scores, ranging from $0-9$, have been reduced to quartiles, with quartile 1 the least deprived and quartile 4 the most deprived.

In summary, this table confirms the absence of an effect of habitation for men and a marked urban/rural difference for women. It shows a more complex pattern for education, with men and women completing secondary education most likely to smoke, with lower rates among those completing university education. Smoking is also very strongly correlated with heavy drinking and is more common in those who have experienced deprivation. Although not shown in the table, the test for linear trend of smoking with deprivation when all 10 categories are used is highly significant $(p<0.01)$ for both sexes. Church attendance is significantly negatively associated with smoking for men ( $p<0.02$ for trend) but not women. Other analyses, not shown here, show no association with perceived ability to influence one's health, self-declared ethnic origin, or view on whether the economic situation of one's family will be better in five years.

Table 3 Smoking status (\%) by type of settlement

\begin{tabular}{|c|c|c|c|c|c|c|c|c|}
\hline \multirow[b]{2}{*}{ Settlement } & \multicolumn{4}{|l|}{ Male } & \multicolumn{4}{|l|}{ Female } \\
\hline & $\begin{array}{l}\text { Current } \\
\text { smoker }\end{array}$ & Ex-smoker & $\begin{array}{l}\text { Never } \\
\text { smoked }\end{array}$ & $n$ & $\begin{array}{l}\text { Current } \\
\text { smoker }\end{array}$ & Ex-smoker & $\begin{array}{l}\text { Never } \\
\text { smoked }\end{array}$ & $n$ \\
\hline Moscow & 64 & 21 & 15 & 43 & 30 & 6 & 63 & 56 \\
\hline Oblast $^{\star}$ capital $\geqslant 0.5$ million population & 62 & 16 & 22 & 167 & 18 & 5 & 77 & 198 \\
\hline Oblast $^{\star}$ capital $<0.5$ million population & 66 & 16 & 18 & 93 & 15 & 7 & 78 & 116 \\
\hline Other town & 65 & 21 & 14 & 225 & 13 & 14 & 73 & 263 \\
\hline Rural & 62 & 20 & 18 & 190 & 9 & 10 & 81 & 217 \\
\hline
\end{tabular}

*Oblasts are the standard regions in the Russian Federation, typically with a population of about 3-5 million. Source: New Russia Barometer VI, 1996. 
Table 4 Factors associated with probability of being a current smoker

\begin{tabular}{|c|c|c|}
\hline \multirow[b]{2}{*}{ Variable } & \multicolumn{2}{|c|}{ Odds ratio $(95 \% \mathrm{CI})$} \\
\hline & Male & Female \\
\hline \multicolumn{3}{|l|}{ Residency } \\
\hline Moscow & 1.00 & 1.00 \\
\hline$\star$ Oblast capital $\geqslant 0.5$ million population & $0.79(0.38-1.65)$ & $0.51(0.24-1.10)$ \\
\hline${ }^{\star}$ Oblast capital $<0.5$ million population & $0.82(0.37-1.81)$ & $0.28(0.11-0.68)$ \\
\hline Other town & $0.96(0.46-1.98)$ & $0.26(0.12-0.56)$ \\
\hline Rural & $0.86(0.40-1.81)$ & $0.15(0.06-0.35)$ \\
\hline \multicolumn{3}{|l|}{ Education } \\
\hline Primary & 1.00 & 1.00 \\
\hline Vocational & $1.41(0.74-2.67)$ & $1.39(0.43-4.52)$ \\
\hline Secondary & $1.09(0.57-2.12)$ & $1.26(0.38-4.22)$ \\
\hline University & $0.63(0.30-1.34)$ & $0.73(0.19-2.76)$ \\
\hline \multicolumn{3}{|l|}{ Alcohol intake } \\
\hline$<0.25$ litres at least twice a month & 1.00 & 1.00 \\
\hline$\geqslant 0.25$ litres at least twice a month & $2.31(1.60-3.35)$ & $12.09(4.75-30.76)$ \\
\hline \multicolumn{3}{|l|}{ Material deprivation $\dagger$} \\
\hline Quartile 1 (least deprived) & 1.00 & 1.00 \\
\hline Quartile 2 & $1.04(0.67-1.61)$ & $0.97(0.52-1.82)$ \\
\hline Quartile 3 & $1.38(0.89-2.15)$ & $1.62(0.87-3.01)$ \\
\hline Quartile 4 (most deprived) & $1.69(1.06-2.70)$ & $2.00(1.03-3.89)$ \\
\hline \multicolumn{3}{|l|}{ Church-going } \\
\hline Never & 1.0 & 1.0 \\
\hline Very rarely & $0.93(0.64-1.35)$ & $1.25(0.74-2.11)$ \\
\hline Occasionally & $0.59(0.35-0.98)$ & $1.23(0.68-2.20)$ \\
\hline At least once a month & $0.51(0.21-1.24)$ & $0.73(0.25-2.09)$ \\
\hline
\end{tabular}

Each variable adjusted for all others listed in the table.

$\star$ Oblasts are the standard regions in the Russian Federation.

tSee text for definition.

Source: New Russia Barometer VI, 1996.

Table 5 Prevalence of smoking (\%) in Russia from other surveys

\begin{tabular}{llllll}
\hline \multirow{2}{*}{$\begin{array}{l}\text { Age group } \\
\text { (years) }\end{array}$} & \multicolumn{2}{l}{$R$ M } & & \multicolumn{2}{l}{ Karelia study } \\
\cline { 2 - 3 } \cline { 5 - 6 } \cline { 5 - 6 } & Male & Female & & Male & Female \\
\hline $15-24$ & 52.4 & 16.8 & & NA & NA \\
$25-34$ & 70.7 & 17.1 & & 77 & 20 \\
$35-44$ & 66.2 & 11.4 & & 61 & 13 \\
$45-54$ & 59.5 & 6.5 & & 68 & 6 \\
$55-64$ & 49.7 & 2.2 & & 57 & 3 \\
$\geqslant 65$ & 33.6 & 1.2 & & NA & NA \\
\hline
\end{tabular}

Sources: Russian Longitudinal Monitoring Survey (RMLS) Karelia study. ${ }^{5}$

$\mathrm{NA}=$ data not available

\section{Discussion}

The national coverage, and in particular the coverage of rural areas, and the ability to link results with demographic and socioeconomic characteristics, enable these data to provide valuable new information about the pattern of smoking in Russia.

Before discussing the results it is necessary to consider the representativeness of the sample, as the response rate was lower than desired. It is possible that non-responders differed from responders in terms of tobacco consumption. Given the observed association between smoking and heavy drinking and the knowledge that those who drink heavily are least accessible to surveys, it is possible that we have underestimated the prevalence of smoking. Conversely, the close agreement with the characteristics of the population, as estimated by Goskomstat, and with observed voting patterns, suggests that the sample is broadly representative of the Russian population.

The overall patterns of smoking found in this study are similar to those in other recent surveys, summarised in table 5 . For the first comparison, we have analysed data from round 6 (undertaken in 1995) of the Russian Longitudinal Monitoring Survey, a periodic survey of between 10000 and 12000 subjects begun in 1992. Data are in the public domain and accessible via the internet, ${ }^{4}$ where full details of the survey methods are provided. The second source is a survey of a random population sample undertaken in 1992 of the population of Russian Karelia aged between 25 and $64 .{ }^{5}$ Both surveys confirm the much higher frequency of smoking among men than women at all age groups and, among women, the much higher frequency among the young. The frequencies among men are broadly similar in each survey, but the Barometer data give slightly higher frequencies for women. Difference in timing or in regional patterns might explain the lower rates reported in the earlier Karelia study but the reasons for the lower frequencies in the Russian Longitudinal Monitoring Survey are not obvious. In both cases, however, it is possible that there may be effects from minor differences in the wording of questions or to chance.

The relative absence of historical data makes it impossible to determine trends with accuracy, although the age distribution in these studies is consistent with higher rates of smoking in the current generation. One of the few examples of studies from the Soviet period is from the MONICA study, ${ }^{6}$ which reported that, in a survey among those aged 35-64 in Moscow and Novosibirsk during 1984-85, between $46 \%$ and $48 \%$ of men smoked and between $3 \%$ and $12 \%$ of women smoked. The frequency was higher among men in Moscow and among women in Novosibirsk. These results are consistent with the few other sources available. An article using data from 1989 cites figures of $44 \%$ for men and $10 \%$ for women $^{7}$ but does not specify the age range included.

Other research provides more information on smoking among young people. A survey of 4594 school children in Nal'chik $(86 \%$ response) reported that $38.2 \%$ of boys and $11.8 \%$ of girls smoked at least one cigarette per week. ${ }^{8}$ It was reported that there was very little awareness of the adverse health effects of smoking. An earlier survey of smoking among Moscow school children found a prevalence of smoking at least one cigarette in the previous three months equal to $14.4 \%$ of boys aged $10-11$, rising to $53.2 \%$ among those aged 16-17. The corresponding figures for girls were much lower, at $0.8 \%$ and $28.2 \%$ respectively. ${ }^{9}$ One small study reported that smoking is more prevalent among manual workers in Russia. ${ }^{10}$

These results indicate that, among men, smoking varies relatively little with area of residence, urban/rural residence, or education. A possible explanation might be the extensive mixing of the population that has occurred during military service, although this explanation is purely speculative. In contrast, there is considerable variation among women that can be summarised broadly as showing much lower rates of smoking in more traditional areas and higher rates among those exposed to western influences. This, taken with the much higher prevalence in younger women 
and the observation that few in these age groups would have smoked in previous generations indicates the potential for a substantial growth in smoking-related diseases in the future. It will clearly be of great importance to understand better the factors underlying this observation, such as how smoking is perceived and accepted. This will require detailed qualitative research

The very strong association between smoking and heavy drinking among women deserves comment. Work on patterns of alcohol-related mortality in Russia suggests that, for men, there is a relatively smooth gradient across education and employment categories whereas, for women, the adverse consequences of alcohol are concentrated in a small, relatively marginalised group. ${ }^{1 \text { a }}$ In the present study, only $3.3 \%$ of women were categorised as heavy drinkers. Our results suggest that these women are also much more likely to smoke.

The finding of a higher percentage of neversmokers among the oldest group of men could reflect the consequences of high death rates among smokers under age 65 , not only from smoking-related diseases but also from alcohol, given the evidence of an association between the two, although this is speculative.

The results suggest that tobacco will make an increasingly great contribution to ill health and premature mortality among women, for whom smoking has traditionally been rare. Young women are the principal targets of promotional efforts by transnational tobacco companies.

The response to this threat has been limited. Although, officially, tobacco advertising was banned in the Soviet Union in 1980 and sales of cigarettes to those under age 16 was prohibited in 1981, these measures have been widely flouted. ${ }^{11}$ In 1993 a further ban on tobacco advertising in the Russian Federation was approved by the Duma (the Lower House of the Russian Parliament) but the press ministry refused to support it because of the revenue consequences. Subsequently the Association of Russian Advertisers lobbied against the ban, reportedly with financial support from the tobacco industry. ${ }^{12}$ In 1995, the Duma passed another law banning advertising, ${ }^{13}$ proposed by the State Anti-Monopoly Committee, which prohibits advertising on television between $7 \mathrm{am}$ and $10 \mathrm{pm}$. Advertisements should carry a health warning, as should domestic, but not imported, cigarette packs. Even though this is a somewhat weaker policy than an earlier proposal that year by the ministry of health and medicine, it too is not enforced. In practice, there is very widespread promotional activity by western tobacco companies, with extensive use of images that identify smoking with a glamorous western lifestyle. ${ }^{14}$

Since 1991, tobacco prices have been increasing and, since 1994, excise taxes were introduced, as were steep import duties on cigarettes, but not on unprepared tobacco. ${ }^{13}$ The actual consequences of these actions, given the evidence of extensive smuggling, are not well clear.
The extent of penetration of the transnational tobacco industry into central and eastern Europe and the former Soviet Union is clearly of great importance and has recently been reviewed by Connolly. ${ }^{12}$ Consumption of cigarettes produced by western companies has accelerated rapidly in Russia, aided by the near collapse of the local production capacity in 1990 due to a breakdown of distribution networks and spare parts. Western companies rapidly took advantage of this situation with RJ Reynolds, Philip Morris, and British American Tobacco providing an "emergency" supply estimated at 38 billion cigarettes. ${ }^{15}$ This has been reported as causing a 72-fold increase in imports of American cigarettes in the first six months of $1991 .^{16}$ Since 1991, western investment in the tobacco industry has been, at the very least, $\$ 310$ million, ${ }^{12}$ making this the largest western investment in any sector in Russia. As the profits accruing to tobacco companies in the former Soviet Union are very much less than in other parts of the world $(\$ 2.29$ per thousand cigarettes compared with $\$ 15.82$ per thousand in the USA and $\$ 6.03$ in the European Union), ${ }^{17}$ it will be necessary for the industry to increase sales considerably, simply to recoup their investments. ${ }^{12}$

In summary, smoking is very prevalent among young and middle-aged men in Russia and, for this group, is influenced little by geography. It has historically been much less common among women and remains so in the more traditional areas of Russia, although it is increasing rapidly among younger women and especially those in areas exposed to greater western influence. There has been a long-term upward trend in deaths from lung cancer among men to what are now extremely high levels by international standards. The long-term upward trend in deaths from lung cancer among women has so far been more gradual, but the evidence of a recent increase in smoking among younger women is likely to feed through to much higher mortality rates in the future.

The New Russia Barometer Survey is undertaken by the Centre for the Study of Public Policy, University of Strathclyde. This work was undertaken as a subsidiary study to a major piece of work on adult mortality in Russia funded by a grant from the UK Department for International Development. However, DfID can not accept any responsibility for any information proDfID can not accept any rest
vided or views expressed.

1 Perlez J. Cigarette maker's smokey haven: Eastern Europe. International Herald Tribune 1997 Jun 25:2.

2 Peto R, Lopez AD, Boreham J, et al. Mortality from smoking in developed countries 1950-2000. Oxford: Oxford University Press, 1994.

3 Rose R. New Russia Barometer VI: after the presidential election. Studies in public policy No 272. Glasgow: University of Strathclyde, 1996.

4 The Russian Logitudinal Monitoring Survey. <http:// www.cpc.unc.edu/projects/rlms/proj_desc.html>

5 Puska P, Matilainen T, Jousilahti P, et al. Cardiovascular risk factors in the Republic of Karelia, Russia, and in North Karelia, Finland. Int F Epidemiol 1993;22:1048-55.

6 The principle investigators. The MONICA Project: a worldwide monitoring system for cardiovascular disease. In: WHO: world health statistics annual. Geneva: World Health Organization, 1989:27-149.

7 Piha T, Besselink E, Lopez AD. Tobacco or health. World Health Stat Q 1993;46:188-94.

8 El'garov AA, El'garova LV. Otnoshenie shkol'nikov Nal'chika k vrednym privychkam. Ter-Arkh 1994;66:45-8

9 Prokhorov AV, Alexandrov AA. Tobacco smoking in Moscow school students. Br $\mathcal{F}$ Addict 1992;87:1469-76. 
10 El'garov AA, Zhasminova VG, Konstantinov VV, et al. Chastota ishemicheskoi bolezni serdtsa i faktorov ee riska Chastota ishemicheskoi bolezni serdtsa i faktorov ee riska u muzhchin 20-54 let-rabotnikov fizich

11 Prokhorov AV. Geting on Smokin' Route 66: tobacco promotion via Russian mass media. Tobacco Control 1997; 6:145-6.

11a Chenet L, Leon D, McKee M, et al. Death from alcohol and violence in Moscow: Socio-economic determinants. Eur f Population 1998. (In press)

12 Anon. Tobacco or health: first global status report. Geneva: World Health Organisation, 1996:EUR-78-EUR-80.
13 Hurt RD. Smokin' Russia: what do Stalin and western tobacco companies have in common? Mayo Clin Proc 1995;70:1007-11.

14 Prokhorov AV. Smoking in Russia. Copenhagen: World Health Organisation European Regional Office, 1993 .
Anon. The pushers are coming! The pushers are com5 Anon. The pushers are coming! The pushers
ing! . . To Russia. Tobacco Control Int 1992;1:9.

16 Connolly GN. Tobacco, trade and eastern Europe. In: Slama K, ed. Tobacco and health. London: Plenum Press, 1996:51-60.

17 Stevenson RW. Tapping a rich smoking frontier. New York Times 1993 Nov 12:D1.

\section{think about second-hand smoke...}

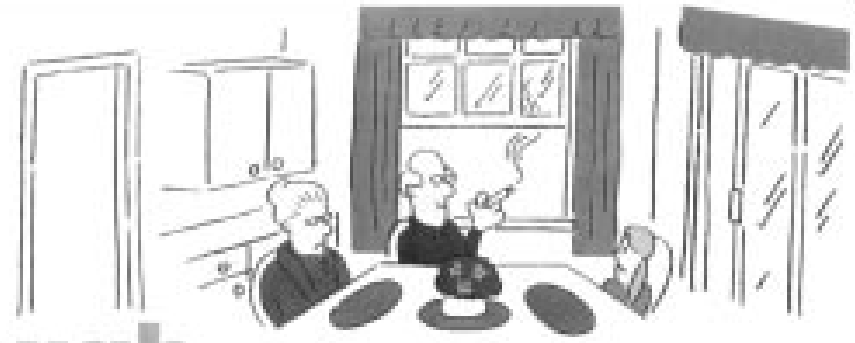

it's IIOt CHOUICH to open a window

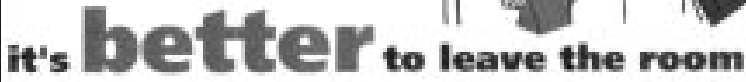
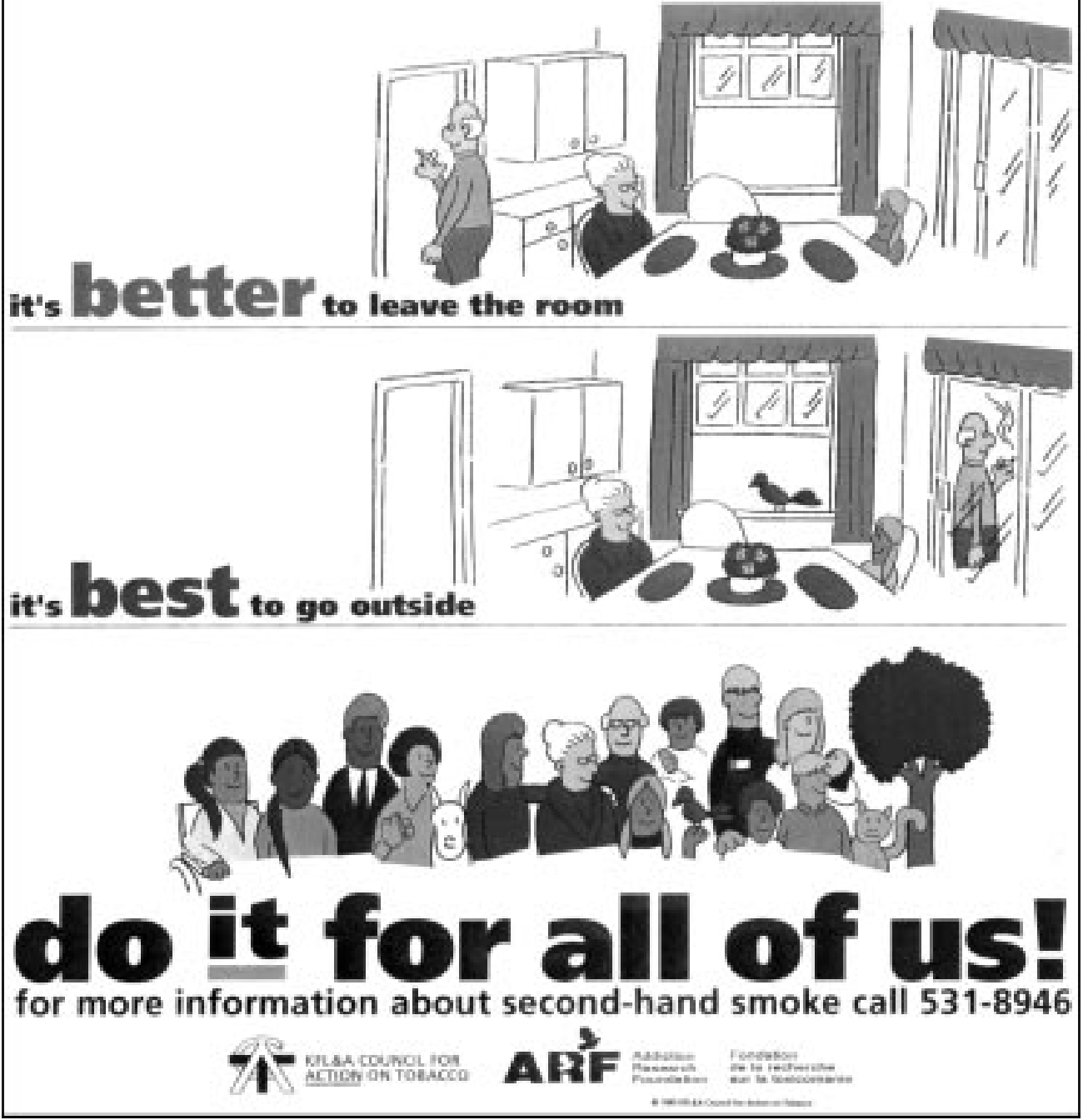